\title{
Sterilisations at delivery or after childbirth: addressing continuing abuses in the consent process
}

\section{Sam Rowlands}

Faculty of Health and Social Sciences, Royal London House, Bournemouth University, Christchurch Road, Bournemouth, BH1 3LT, UK

Email: srowlands@bournemouth.ac.uk

Telephone: (0)1202 962782

ORCiD: 0000-0001-5940-9079

Twitter: @ rowlands999

\section{Jeffrey Wale}

Centre for Conflict, Rule of Law \& Society, Faculty of Media and Communication, Weymouth House, Bournemouth University, Fern Barrow, Poole, BH12 5BB, UK Email: jwale@ bournemouth.ac.uk

Telephone: (0)1202962245

ORCiD: 0000-0002-9210-029X

\section{Corresponding author:}

Sam Rowlands 
Pre acceptance version

\section{Word count}

Abstract: 175 words

Main text: 6940 words

References: 1098 words

\section{Keywords}

Consent, delivery, ethics, human rights, sterilisation 


\begin{abstract}
Non-consensual sterilisation is not only a historic abuse. Cases of unethical treatment of women around the time of a pregnancy continue in the Twenty-First Century in five continents. Sterilisation is being carried out by some healthcare professionals at the time of delivery, or soon afterwards, without valid consent. A range of contemporary examples of such practices is given. Respecting women's autonomy should be the touchstone of the consent process. Avoidance of force, duress, deception and manipulation should go without saying. Ethnic minority communities and women living with HIV, in particular, are being targeted for this kind of abuse. Attempts have been made in various countries and by international professional organisations to introduce clinical guidelines to steer health professionals away from this malpractice. Survivors have sought justice in domestic and international courts. This paper critically assesses the evidence on the practical, ethical and legal issues around the handling of consent for these procedures. Suggestions are made about possible regulatory responses that address abuse, whilst maintaining access for those individuals who freely elect to undergo these procedures.
\end{abstract}




\section{Introduction}

Historical sterilisation abuses were concentrated in the first four decades of the Twentieth Century, particularly in jurisdictions with eugenic laws (Amy and Rowlands, 2018a, 2018b). However, abuses on a smaller scale have been identified from 38 countries in the TwentyFirst Century (S. Rowlands and J.-J. Amy, 2018). Respecting women's autonomy should be the touchstone of the consent process but there remains ongoing evidence in some countries (low-resource through to high-resource) of obstetrician-gynaecologists performing female sterilisations in circumstances in which the woman's consent is dubious or invalid (S. Rowlands and J.-J. Amy, 2018). There is also evidence that ethnic minority communities, women living with HIV and other marginalised groups are being targeted for this kind of abuse (Solinger and Nakachi, 2016). Intersectional attributes or identities - both physical and social - may contribute to and feature in these abuses of power and complicate any subsequent analysis and regulatory response (Cooper, 2016; Curran, 2016; Sifris, 2016).

This paper examines contemporary evidence about sterilisations carried out on women who are being delivered of a baby or immediately thereafter. Our primary focus is on nontherapeutic surgical intervention, or at least those cases where there is no therapeutic basis for intervention in the case of a particular woman (i.e. no medical condition such as fibroids or heavy menstrual bleeding is being explicitly treated by the procedure). All references will therefore be to cases where the sterilisation is undertaken solely to control fertility.

This paper is in five parts. The first part presents Twenty-First Century examples of nonconsensual sterilisation. In part two, we look at legal and ethical aspects of the issue. In part 
three, we examine the positive action that has been taken to date, including the drafting of clinical guidelines. In part four, we suggest possible regulatory responses and in part five we draw together our conclusions.

\section{Contemporary examples}

In this part, we have conducted a literature search for non-consensual peripartum female sterilisation between the years 2000 and 2017. We identified reports of sterilisation abuses around the time of childbirth from five continents. Most of these are not isolated cases, but small clusters or larger collections of similar cases. There are doubtless many more examples that have gone unreported. We mention here only those examples that have been welldocumented or have been the subject of legal proceedings. These cases demonstrate that the women being targeted for sterilisation around the time of delivery frequently belong to marginalised population groups (Patel, 2017) or are subject to repressive state control. Whilst any suggestion that pregnant women are vulnerable as a class is contentious and disputed (Beauchamp and Childress, 2013), the circumstances around and immediately after childbirth (for example, ongoing pain) may make some women and groups of women acutely vulnerable at this time (FIGO, 2015). This picture may be further complicated by intersectional concerns where the women involved belong to more than one marginalised group within a community.

For the avoidance of any doubt, we are not seeking to undermine or diminish women as autonomous agents at the time of or around childbirth. However, we do argue that the process of seeking consent requires particular care where the consequences are irreversible 
and permanent for the women involved. There may very well be circumstances during or after the birth process that undermine the essential requirements of valid consent, including the ability to carefully weigh competing alternatives and the advantages/ disadvantages of specific courses of action. Of course, these concerns might apply equally to other types of surgical decision-making entailing irreversible, permanent and life changing outcomes. The life changing nature and experiential dimension of the decision-making may prove critical in any case (Dunn, Fulford, Herring, \& Handa, 2018). Healthcare professionals should always be alert to the fact that sterilisation involves an acutely sensitive and personal decision to give up the ability to reproduce.

The actions of health and social care staff in the following cases include violations of the right to health, the right to bodily integrity, the right to be free from violence, the right to be free from torture and inhuman and degrading treatment, the right to decide on the number and spacing of children and the right to be free from discrimination (see Convention on the Elimination of All Forms of Discrimination against Women 1979, Article 16).

\section{Europe}

Roma women were found to have been disproportionately subjected to non-consensual sterilisation at the time of childbirth since the turn of the century in three central European countries: the Czech Republic, Hungary and Slovakia (Zampas and Lamačková, 2011). In this paper we will take the Czech Republic as our example. In this country there have been examples of absent, forged and forced consents for sterilisation in the peripartum period (ERRC, 2016). 
In 2001, a Czech Roma woman aged 19, Helena Ferenčiková, was on the brink of giving birth to her second child by caesarean delivery. She was asked by a doctor to give oral consent for sterilisation after having been given an alarmist warning that she would die if she went through childbirth again; she was already premedicated and the exact timing of this 'consent' was 31 minutes before surgery (Motej1, 2005). This was invalid consent (Holt, 2005) by several standards because of the absence of accurate/ correct information, the directive nature of the guidance and the presence of premedication. These create doubt that the decision to undertake the procedure was a 'free and informed' one. Ferenčíková sued the hospital in the Czech courts for violation of her personal integrity (Zampas and Lamačková, 2011). She won her case in 2007, the High Court in Olomouc ordering the hospital to provide her with a written apology. It was determined that she was not entitled to compensation due to the statute of limitation. The Vitkovicka hospital in Ostrava apologised two months later. Ferenčíková filed an application to the European Court of Human Rights (ECtHR) regarding her lack of compensation and the case is pending. The Czech government has since awarded her $€ 10,000$ in a 'friendly settlement' (ERRC, 2016).

\section{North America}

Four indigenous women in the Canadian province of Saskatchewan felt pressurised into having sterilisations associated with childbirth during the time period 2005 to 2010 and 'went public' with their grievances. As a result of extensive publicity, the Saskatoon Health Region modified its consent protocols in 2015. An external review was ordered into the circumstances of these sterilisations and others who might have been similarly treated were asked to come forward (Crozier, 2017). The review was carried out by two well-respected and highly-qualified Métis women and was published in July 2017 (Boyer and Bartlett, 


\section{Pre acceptance version}

2017). From in-depth interviews of a sample of seven recruited women, it was clear that medical staff abused their power and discriminated against Aboriginal women and that the women felt powerless. Coercion was relentless over time; saying 'no' made no difference. The prominent role of social workers in the coercion was exposed. The women spoke of deep-seated negative emotional personal impacts, as well as impacts on their relationships with their partners. A number of Calls to Action were included at the end of the report. These included mandatory cultural training to address false stereotypes such that Aboriginal women are incapable of 'proper' motherhood or of making their own decisions. The Health Region apologised to all the women affected, but no compensation was paid. A class-action was started by lawyers in 2017 on behalf of women affected in at least one other Canadian province in addition to Saskatchewan (CBC, 2018).

\section{South America}

Women living with HIV are particularly targeted by healthcare professionals in Chile; a 2004 study found that $42 \%$ of such women had been sterilised without valid consent (Nair, 2011). In particular, there is evidence of coercion of women living with HIV in Chile to have sterilisations at the time of delivery (Anonymous, 2010). The case of Francisca, a woman living with HIV, was taken to the Inter-American Commission on Human Rights in 2009 by the Center for Reproductive Rights and Vivo Positivo. Her case, FS v Chile, is still pending at the time of writing (S. Rowlands and J. J. Amy, 2018). Francisca was 20 years old when she was sterilised with a complete absence of consent (oral or written - Chilean law requires written consent) during a caesarean delivery in Curicó in 2002. In 2007, she filed a complaint against the surgeon, but despite a police investigation confirming that she had not given consent, the Public Prosecutor dismissed the case. She then exhausted all her domestic 
remedies in the Chilean court system; an appeal to a higher court was unsuccessful (Nair, 2011).

\section{Africa}

Women living with HIV in Namibia have been sterilised without any consent, coerced into consenting in order to be able to access maternity services, asked to consent while in labour, given little or no information, not given other options or given a form in a language they do not understand. The findings of the 2008 International Community of Women living with HIV/AIDS study in Namibia (ICW, 2009) resulted in a government investigation; this found no wrong-doing (Nair, 2011). Not content with this outcome, ICW and the Legal Assistance Centre filed a total of 16 lawsuits against the Ministry of Health and Social Services as well as the three hospitals in question.

In 2012, three of the 16 women living with HIV each sued the Namibian government in the High Court (S. Rowlands and J. J. Amy, 2018). All three had been sterilised in public hospitals in the mid-2000s at the time of a caesarean delivery. The women alleged violations of a range of constitutional rights, lack of valid consent and discrimination based on their HIV-positive status. The Namibian High Court ruled that there was evidence that the women had been sterilised without valid consent but found insufficient evidence that they had been discriminated against because of their HIV status (Badul and Strode, 2013).

The government appealed to the Supreme Court, which upheld the High Court ruling in 2014. The Supreme Court judgment, Government of the Republic of Namibia v LM and others ("Government of the Republic of Namibia v LM and others 
http://www.saflii.org/na/cases/NASC/2014/19.html ", 2014), was a landmark decision.

Although the women had signed consent forms for "caesarean section and BTL (abbreviation used in the case for bilateral tubal ligation)", it was ruled that consent could not have been valid when (i) the women were in labour, (ii) the procedures had not been properly explained to them (use of abbreviations and lack of Oshiwambo interpreters contributed to this) and (iii) there was no opportunity to weigh options. The Supreme Court did not find discrimination based on HIV status but deplored medical paternalism as specifically harmful to the three women in this case and more generally. Legal scholars have suggested that, not only did the Court miss an opportunity to consider the human rights implications of forced sterilisation, but that a case for gender-based violence should have been mounted by the lawyers acting for the women (Durojaye, 2017).

\section{Asia}

Countries with population policies such as China and India (Solinger and Nakachi, 2016), whose sterilisations each year number in the millions, will doubtless include many cases of non-consensual sterilisation around the time of childbirth, but such cases have hardly ever been explicitly reported on. We will therefore confine ourselves to the central Asian republic of Uzbekistan.

Under the authoritarian leadership of Islam Karimov, who died in September 2016, very little information has reached the outside world. It has been directed, under a confidential internal decree dating from 2000, that Uzbek women should be sterilised after they have had two children, in order to control the population. The most recent sterilisation campaign in Uzbekistan began with decree 1096 of 13 April 2009 which, although not mentioning the word 'sterilisation', couches its population policy in terms of 'prophylactic-explanatory work 
regarding the health of mothers and children'. Contraception and sterilisation is the remit of 'dispatch brigades' sent out to all parts of the country (Antelava, 2013).

Reliable information has been difficult to obtain - usually the source has been interviews with individual doctors or women who have undergone sterilisation who are prepared to take the risk of speaking out. Reports of forced sterilisations did not emerge until 2005; the existence of non-consensual sterilisation is denied by the government (Antelava, 2013). It appears that it is mainly doctors rather than lay motivators who recruit acceptors. Subsequently it appeared that the Uzbek government set verbal quotas on performance of 'voluntary surgical sterilisation'. This involved attempting to secure consent but in most cases women were being pressured, deceived or even threatened (Holt, 2012). A woman called 'Nargiza' said that she signed a consent form when under the influence of premedication prior to a caesarean delivery for her second child; doctors told her the piece of paper was merely a 'thank you letter' to the hospital. Sterilisation at caesarean delivery was 'automatic'. It seems individual gynaecologists are allocated quotas such as four procedures per month each. Caesarean rates have risen, probably as a result of gynaecologists needing to meet their quotas. Women of reproductive age coming into hospital for unrelated problems such as appendicitis have also been pressured into being sterilised. The issue of forced sterilisations and hysterectomies was brought to the attention of the UN committee against Torture in 2007 and again in 2013.

\section{Ethical and Legal Aspects}

Having set out a range of contemporary sterilisation abuses, we now move on to consider the ethical and legal aspects of valid consent in more detail. It is a core bioethical principle that patients should consent to their medical treatment and that such consent should be both free 
(voluntary and not unduly influenced, pressured or coerced) and informed (based on sufficient and material information with an opportunity for discussion) (Beauchamp and Childress, 2013). This principle presupposes that the primary decision-maker is the patient and that they have the capacity to make the relevant choices/ decisions around treatment and, in the case of sterilisation, whether to refuse or to consent to that invasive procedure.

\section{Problematic cases}

We have already encountered a range of examples but, for the purposes of discussion, it is probably helpful to divide the problematic consent cases into three main categories, although we accept that there is some scope for conflation between them. First, there are those cases where the healthcare professional performs the medical procedure without any patient consent or attempts to obtain it in circumstances where that person does not have the capacity to validly consent at the material time. Secondly, there are those cases where there is an issue with the information supplied to the patient, such that the decision-making and consent process is based on false or inadequate or incomplete information. This category can be further subdivided, depending on the motives and aims of the information provider. In this specific category, the patient might assert that there was no valid consent to the procedure because of the falsity and/or paucity of information, or they might alternatively argue that the healthcare professional was simply careless in the supply of information without invalidating their consent. The materiality of the information supplied (or withheld) might tip the balance one way or the other.

Thirdly, there are cases where patient agreement to the proposed medical procedure is more appropriately framed as one of 'submission' - where the agreement has been obtained via the use of threats, coercion or other promises to withdraw benefits/ services or impose detriment. 
The offer of incentives or rewards might also be included here, although this is an even more problematic area (Beauchamp and Childress, 2013). Clearly, there will be examples where it is difficult to separate the 'free' from the 'submission' case, recognising that subtle forms of social pressure exist in all aspects of our lives that cannot be entirely excluded from the decision-making process. Healthcare professionals may think it important to advance or even exaggerate the merits of a procedure which they genuinely believe is in the best interests of their patient. However, there will come a point when reasonable persuasion crosses the line into improper coercion. Although we may have clear intuitive responses to many of the examples in this paper, it can still be difficult to draw a clean bright line between proper and improper pressure in certain cases. However, as we shall see, certain features of sterilisation may help point the way. Finally, it is important to recognise the subjective nature of patient responses to pressure and persuasion - the critical issue is whether healthcare professionals are acting in a way that undermines the self-autonomous and directed decision-making of the patient (Beauchamp and Childress, 2013). Mutual trust is important to the therapeutic relationship and requires professionals not to abuse their social authority and to ensure that patient autonomy is respected. Healthcare professionals are important guardians of this autonomy - a position which imposes an ethical obligation requiring specific recognition of the potential vulnerability sketched out above. Clinicians should exercise considerable care around the obtaining and implementation of consent to sterilisation during and immediately after childbirth. Circumstantial features - including ongoing pain (FIGO, 2015) and intersectional attributes - also need to be weighed in the balance when deciding whether a woman is capable of making a free and informed decision, taking into account the gravity and nature of the choice/ procedure concerned.

\section{Some preliminary considerations}




\section{Pre acceptance version}

Before going any further, it might be helpful to highlight a few preliminary considerations around consent for female sterilisation. The issue of capacity is potentially problematic for a woman in the final stages of pregnancy and its immediate aftermath. She may be in considerable pain and using central nervous system depressant medication for this. There may be considerable anxiety over the welfare of the unborn or born child, as well as anxiety about her own wellbeing. Capacity is decision-specific and subject to fluctuation - there may be some variance around the capacity to consent to short-term options (e.g. medication, mode of delivery) and longer term and potentially irreversible decisions impacting on fertility. Again, we should make it clear that we are not suggesting that women do not have the capacity to make any decisions around or after childbirth - rather that certain type of decisions (those with permanent, life-changing and acutely personal outcomes) require healthcare professionals to take particular care to ensure that the patient has the necessary capacity and understanding to make a decision of that specific nature (including its permanent outcome). This needs to be borne in mind when the medical need is non-urgent, even if there are or may be potential benefits for the woman in acting immediately (e.g. because it will avoid a second operation). However, it is equally important that healthcare professionals should not be using patient capacity as a guise or contriving 'therapeutic' grounds - whether motivated by best interests or otherwise - to override the 'free' or ‘informed' elements of consent (Beauchamp and Childress, 2013).

Sterilisation procedures are usually irreversible and therefore create a permanent outcome for the woman. The availability of reversible and reliable alternatives of contraception may be an appropriate and material consideration for patients and clinicians. These options should not be imposed on a woman, any more than sterilisation should, but they ought to be outlined as a viable choice before any action is taken that produces a permanent state of affairs. 


\section{Pre acceptance version}

Fertility-focused sterilisation procedures are also by their very nature non-urgent (elective) healthcare professionals cannot justify these interventions purely on necessity grounds because 'best interests' are not sufficient to sidestep patient consent when there is no medical emergency. This is an important factor when coupled with the permanency and life-changing nature of the procedure. The right to reproduce and to avoid pregnancy (and information thereto) is a fundamental human right - one that goes to the core of our humanity - and any deprivation of that right demands careful and specific justification by a State and/or its agents (see Convention on the Elimination of All Forms of Discrimination against Women 1979, Article 16). Sterilisation not only removes a person's reproductive capability but may also create a stigma or create a value judgement on their worth within society. We must always be alert to the potential discriminatory effects of female sterilisation, especially for marginalised groups and those with intersectional identities/ attributes (Cooper, 2016).

We should pause here to address academic and representative body arguments that nontherapeutic postpartum sterilisations should be categorised as emergency/ urgent procedures (Richardson, Hall, \& Zuckerwise, 2018). It is acknowledged that there may be hurdles for women to overcome - including funding and insurance requirements - before they can secure access to a postpartum sterilisation. Whilst it might be advantageous to categorise these types of procedures as 'urgent' for funding or access purposes, the core problem is the funding/ access arrangements themselves. It is also artificial to categorise an entire class of medical procedures based on speculative consequences. However, the real issue is that categorising postpartum sterilisations as urgent (irrespective of factual need) creates the opportunity for clinical abuse. Converting or categorising non-urgent procedures into 'urgent ones' for access or funding purposes, sets up an environment for healthcare professionals to 
override or otherwise abuse default consent processes. In our view, the better solution is to address the access or funding arrangements directly rather than by shoehorning procedures into artificial categories.

Finally, we should not ignore the potential for patient regret after sterilisation. This regret may well be exacerbated if the woman has not been involved in a free and informed consent process (Chi and Jones, 1994; Clinical Effectiveness Unit, 2014). However, it is arguable that regret is the wrong term to use for an aggrieved woman in whom the consent or consent process was defective (Denbow, 2015). Of course, regret is not unique to sterilisations but, again, the acutely personal and life-changing nature of the interference is an important factor. Further, we must always be careful to differentiate between situational regret (about external factors motivating a treatment decision that are beyond the control of the healthcare professional) and decisional regret (where the patient wishes, with the benefit of hindsight, that they had made a different decision) (Watson, 2014). It is decisional regret which healthcare professionals can influence and learn from.

\section{Ethical arguments}

Having sketched out this background, let us move on to develop the specific ethical arguments around the handling of consent in sterilisation. It is important to emphasise that bioethical discourse ought to take cultural differences into account, and to recognise that different societal priorities and perspectives may be placed on concepts of autonomy. However, we also need to make it clear that differential prioritisation of autonomy should not be used simply as an excuse to promote discriminatory practices against vulnerable sections of society including (for our purposes) some pregnant women. 


\section{Pre acceptance version}

Deontological ethical approaches - that hold that doing the right thing entails that one should respect the rights of fellow agents, or that one should act in accordance with one's duties to self and others - generally underpin the value and importance of informed consent prior to and during the procedure. Imposing sterilisation without valid consent clearly impinges upon a patient's right to self-determination and ignores the reciprocal duties that are owed by doctors to their patients to promote and ensure autonomous treatment. For the sake of transparency, our own personal emphasis is clearly on respecting individual autonomy in the consent process.

Teleological ethical approaches - that hold that one should act in whichever way promises to promote some desirable 'state of affairs or good', such as general welfare or utility - may prioritise principles of beneficence (whether they be patient-centric or more generalised concepts of societal benefit) over autonomy. We have already encountered these ethical approaches when discussing intersectionality (which it has been argued has a 'teleological aim to expose and dismantle dominant systems of power' (Cooper, 2016)) and the categorisation of postpartum sterilisation as an urgent procedure (by drawing upon wider concern about unintended consequences, access and funding concerns (Richardson, et al., 2018)). This form of ethical discourse offers the greatest scope to minimise the importance of patient choice, personal autonomy and consent. However, we have already seen the limitations of the 'necessity' type argument with capable decision-makers in a nonemergency scenario. Where best interest arguments are deployed, they can have little to do with promoting individual patient welfare and be more about the promotion or alleviation of generalised social or resource factors (Richardson, et al., 2018). There are certainly social welfare points that can be made to support expedited sterilisation procedures. A single operative procedure may be a prudent use of scarce medical resources in low-resource States 
and assist patient access. However, we should be careful not to confuse or conflate the arguments for the fair allocation of public health service resources with the non-consensual imposition of those services. In low-resource countries, maternal mortality and morbidity are high and women from rural communities may present to a medical facility for delivery only, giving just a single window of opportunity for peripartum sterilisation. Some argue that this factor alters the balance of what is ethical, when a missed opportunity to perform sterilisation might be followed later by a maternal death (D. A. A. Verkuyl, 2015). However, it is problematic to use a potential risk of harm to justify an actual harm to that individual. Whether these or other factors can ever be sufficient to override the requirement of valid consent in the competent patient is moot (it is certainly not a position that we endorse); such cases and any supporting policies would need very careful and weighty justification by a State and its agents. Further, even where there is public support, 'paternalistic governmental policies or healthcare practices are susceptible to abuse if they lack high-level public scrutiny' (Beauchamp and Childress, 2013). So, for the avoidance of any doubt, we are deeply suspicious and/or cautious about the use of teleological ethical approaches that undermine patient autonomy in the sterilisation context.

For the sake of completeness, we should also address the Beauchamp and Childress 'principilism' model that articulates a hybrid ethical approach, and which has been and continues to be popular in the healthcare field. Their principles of autonomy and justice are usually associated with deontological ethics, whilst beneficence and non-maleficence are more usually associated with teleological ethics. The irreversibility of sterilisation - a plain harm to the competent patient and in our view a breach of personal autonomy when undertaken without consent - makes non-therapeutic intervention difficult to justify on beneficence grounds alone, particularly where there is reasonable scope to seek that 
permission. The ethical principle of justice can be interpreted in many ways, but when framed in consequential, distributive and economic terms may provide a means to undermine the requirement of valid consent, although it would still need to be balanced against the other core ethical principles in the Beauchamp and Childress model. It would also need to take the vulnerability and potential discrimination against the group(s) involved into account. This may strengthen the argument that State actors and healthcare professionals should bear a heavy burden in justifying any interference with the requirement for consent in these nonurgent and potentially irreversible procedures (Beauchamp and Childress, 2013). This does not mean that healthcare professionals should be compelled to act in circumstances which they do not regard as being in the patient's best interests. If they genuinely believe that sterilisation is in a patient's best interests, but valid consent is not forthcoming, there may be an obligation to refer that patient to another professional if they do not feel able to respect the patient's wishes.

Having highlighted the central importance of respect for individual autonomy in the consent process, we now move on to consider the specific legal responses that might need to be addressed by State actors in the context of sterilisation.

\section{Specific legal responses}

Legal consent processes can be helpful - they can be used by healthcare professionals to demonstrate that there has not been any deception, coercion or manipulation on their part (Manson and O’Neill, 2007). Different types of law (civil or criminal) may be enacted that address the effect and impact of consent in varying ways. For example, States may wish to limit the ability of individuals to consent to certain levels of harm by use of the criminal law. This may be subject to exceptions depending on the nature of the actor, the nature of their 


\section{Pre acceptance version}

actions and their overriding motives. States may want to differentiate consensual invasive surgery that is deemed proper medical treatment from lay individuals who choose to inflict consensual pain and injury for mutual personal pleasure (Fovargue and Mullock, 2016). Whether such distinctions can be ethically maintained is another matter.

Again, States may want to set requirements around what constitutes adequate informed consent - what level of information should be disclosed and in what form? So, the law might require disclosure of all material benefits/ risks and alternative treatment options (e.g. information about the availability of reversible forms of contraception) to be conveyed to the patient in a timely fashion before securing consent and the undertaking of any sterilisation procedure.

Other practical considerations for the law to address might include:

- The appropriate allowance for changes of mind and withdrawal of consent (Gilliam, Davis, Berlin, \& Zite, 2008).

- The appropriate time intervals between imparting information and obtaining consent and then between the consent and the operation (Soares and Brollo, 2013). A balance will need to be struck to ensure that any interval does not unduly fetter patient access.

- The use of standardised written consent forms and the appropriate literacy levels employed (Zite and Wallace, 2011). The avoidance of medical jargon (Clements, 2005) and abbreviations. Arrangements that address language and communication difficulties or issues (Hunt and de Voogd, 2007).

- The appropriate allowances for cultural differences (Gostin, 1995).

- The appropriate mechanisms for identifying hidden forms of pressure - for example, from within the family. 
- The appropriate mechanisms for patient complaints and to address national policies that might put pressure on health care professionals to act in a particular way.

\section{Positive Action to Date}

In this part, we examine the positive steps that have already been taken to address the abuse of consent in female sterilisation. We offer both international (WHO/ FIGO) and domestic (US) guidance as examples.

Human rights bodies have called upon States to take all appropriate measures to prevent coercion in relation to fertility and reproduction and to provide effective remedies when such violations occur (WHO, 2014). They have specified that these measures may include clarifying and strengthening legal frameworks that clearly define full, free and informed consent; ensuring that such measures are well understood among healthcare professionals and by the public; and the training of healthcare professionals on patients' rights (WHO, 2014).

Guidelines on consent for sterilisation have been drawn up by both national and international professional bodies, starting several decades ago. A US Federal guideline listing criteria for Federal reimbursement of the costs of the procedure was produced in 1978 and came into force in 1979 (Petchesky, 1979). The guideline included the following stipulations:

- the woman must be aged 21 or over

- no-one who is deemed lacking in mental capacity should be sterilised

- those in institutions or prisons are only to be sterilised if authorised by a court or review committee

- a 30-day waiting period must be observed between consent and the procedure 
- the consent should not be obtained when a woman is vulnerable such as when requesting an abortion, going into labour or in the aftermath of delivery

- the consent form to be written in a patient's primary language; otherwise an interpreter to be used if the patient cannot understand the language of the consent form

- written confirmation should be given to a woman that she will not have her welfare benefits cancelled if she declines the procedure

- hysterectomy is not considered to be a valid form of fertility control

The International Federation of Gynecology and Obstetrics agreed in March 2011 that the following further points are essential to observe when obtaining consent to sterilisation (FIGO, 2015):

- consent must be freely given and adequately informed

- third parties such as husbands, parents, legal guardians, doctors and health officials cannot give consent on behalf of a woman (the laws of some countries contradict this)

- consent must not be a condition to access to treatment e.g. for HIV infection, to social assistance or to release from an institution

- it is unethical for healthcare professionals to perform a sterilisation within the framework of a government programme where the consent is not voluntary

- concern about the risks that a future pregnancy might expose a woman to is not a valid ground for performing a sterilisation

- it must be explained that sterilisation is permanent and that reversible alternatives are available 
We should highlight two immediate issues with this guidance. First, the US Federal waiting period has proved problematic for access and funding purposes (Richardson, et al., 2018). It presumes that decision-making during this period is defective. Our position is that whilst postpartum sterilisation decisions do raise specific issues for the treating healthcare professionals, the mere proximity of the birth does not negate the validity of consent by default. Many women will be quite capable of making free and informed decisions about their fertility within the 30-day waiting period, providing of course that the other elements of valid consent are respected. In these cases, waiting periods will act as an unwarranted hurdle to patient access. Secondly, whilst the risk of future pregnancy may not be a valid ground for undertaking sterilisation without valid consent, it may nonetheless be a reasonable ground for a patient to request a sterilisation or otherwise reasonable for a healthcare professional to raise the issue in any discussion around options for contraception.

\section{Possible Regulatory Responses}

In this part, we examine a range of general regulatory responses that might be used to address continued non-consensual sterilisation abuses. At the outset, it is important to emphasise the need for a balance to be struck by State actors in this area - there is the risk that overly protective regulation and unduly cautious healthcare responses may impede women's access to sterilisation. A Dutch study showed that $78 \%$ of women undergoing caesarean delivery who would have wanted a combined caesarean delivery and sterilisation missed the opportunity to have this because the subject was not raised (D. A. Verkuyl, van Goor, Hanssen, Miedema, \& Koppe, 2011). A US study found that $48 \%$ of women who had had a vaginal delivery did not get the sterilisation they had requested antenatally, often because the mandatory US 30-day waiting period had not elapsed (Wolfe, Wilson, Hou, \& Creinin, 2017). There is also the need for a balance between the various policy choices available to 
State actors - what is paramount is that the decision-making process remains patient-centred and respectful of maternal autonomy.

International legal instruments (e.g. Convention on the Elimination of All Forms of Discrimination against Women, 1979) and medical guidelines (e.g. FIGO, 2015) undoubtedly have a valuable role to play in preventing abuse and co-ordinating/ targeting domestic regulatory responses. They can also provide a valuable route of redress where domestic mechanisms fail to provide adequate protection and effective remedies for the women involved. However, international mechanisms are usually less effective and immediate than domestic forms of regulation and it is therefore imperative that domestic regulatory frameworks are clarified and strengthened. In the following section, we will focus on four broad policy approaches (or policy instruments) open to domestic State actors that can be used to address continued non-consensual sterilisation abuses. The usual regulatory wisdom suggests that multiple policy approaches tend to work better than singular approaches.

\section{Authority}

Authority-based policy responses usually involve 'hard' forms of regulation; these can take the form of legal or professional regulation and can be framed in negative or positive terms. As we have seen, the obvious target for this type of regulation is the information sharing and consent processes around the sterilisation procedure (and medical procedures generally). Legal mechanisms may be preferable if there is evidence that professional regulation is not proving effective or if the professional regulators are out of step on key points. There is also a role for the law in establishing effective forms of redress and remedy in the event that abuse does occur. The relative balance between legal and professional regulation will be a Statecentric decision but our preference would be that measures should be constructed in tandem 
and not in isolation. Legal mechanisms and sanctions may also be preferred when addressing and expunging wider discriminatory practices within society.

Mandatory waiting periods have been used in some jurisdictions to provide a space for the assimilation of information and unhurried decision-making. However, as we have seen, these approaches can work against individual autonomy (by causing delays and obstructing access to care) and be discriminatory if applied against certain groups of patients. A good example of the latter is the Federal application of a waiting period against women in the US Medicaid scheme (Borrero, Zite, Potter, Trussell, \& Smith, 2013; Moaddab et al., 2015; Richardson, et al., 2018). On balance, we do not support the use of mandatory waiting periods because of the potential for adverse impact on patient access.

\section{Informational}

It should be recognised that those individuals and groups most at risk of coercion and pressure are often those whose access to contraceptive services is also restricted or denied. The broad public dissemination of accurate and non-directive educational materials relating to sterilisation and other reversible forms of contraception are clearly important and should be a priority for State actors. This might include information about how these procedures can be accessed and what sort of conditions the women should expect (e.g. waiting periods, duration and the need for hospitalisation). Where sterilisation is the preferred option, State actors can mandate the form of any consent paperwork. In the USA, a low-literacy Medicaid form did lead to better understanding and was generally preferred over the standard form (Zite and Wallace, 2011). It is important that informational approaches address the intersectional concerns that we have highlighted; State actors have a responsibility to ensure 


\section{Pre acceptance version}

that marginalised groups/ identities receive necessary and accessible information about the full range of contraception options available.

Informational policies should also be directed to the healthcare professionals involved - they need adequate training and information about sterilisation procedures, alternative treatment options and the proper mechanisms for handling and achieving valid patient consent. Any training needs to recognise the importance of patients' rights, the importance of respecting autonomy (WHO, 2014) and the need for consistent assessments of capacity that do not exploit pregnant women and which are sensitive to the type of decisions being made (Dunn, et al., 2018). Here, State actors have an important role to play in ensuring equality of access, and in combatting and addressing any systemic discrimination against marginalised groups of patients.

\section{Organisational}

Organisational policy instruments ought to address domestic access to sterilisation procedures. They would need to ensure that adequate resources are provided to deliver sterilisations and to guarantee that, on a practical level, healthcare professionals have adequate time and skills to effectively address the consent process. Again, specific efforts should be made to address marginalised groups. So, for example, where patients do not speak the same language as healthcare providers, interpretation services ought to be made available within those establishments. Many private companies now offer this facility, with almost immediate connection by telephone to a person speaking a particular language being possible. However, even when using skilled interpreters, it has been shown that it can be challenging to achieve valid consent in these cases (Hunt and de Voogd, 2007). 
National and institutional performance targets can be problematic if they result in undue pressure on healthcare professionals to carry out sterilisation procedures (Sharma, 2014). It might be legitimate to monitor the number of procedures to inform other policy responses, but great care needs to be taken with the use of any performance targets in the context of sterilisation. We would argue that this is especially the case where marginalised groups are, or might be, adversely impacted by a target. States need to be alert to the risk of indirect discrimination either because of disproportionate impact on a marginalised group and/or because those implementing the targets at a local level are likely to be influenced by discriminatory factors.

\section{Incentives}

There may be a place for specific incentives that facilitate better access to sterilisation procedures - for example, free transport and childcare services for those who live in geographically remote areas - but, generally, incentives are problematic if they undermine the personal autonomy of specific individuals or vulnerable groups of patients. The offer or promise of consequential benefits for patients who undergo sterilisation is difficult to justify and should not be used.

\section{Conclusions}

The targeting of marginalised groups of women for sterilisation, for example minority ethnic groups or people living with HIV, is discriminatory. The potential vulnerability of some pregnant women should be recognised; and some pregnant women have attributes and/or identities that make them particularly vulnerable in the context of sterilisation and prey to multiple or intersectional discrimination. Active steps need to be taken on the global and 
domestic stages to address these continuing abuses whilst maintaining access to sterilisation for those choosing freely. Even States with a positive track record of respecting patient autonomy must not be complacent and should still take steps to ensure that this issue remains on the active policy agenda. In this paper, we have identified a range of possible regulatory responses that seek to support and facilitate individual patient autonomy and free and informed consent. Whilst priorities will be influenced by local conditions and ethical starting points, multi-pronged responses are more likely to gain traction and to affect positive regulatory outcomes.

\section{Disclosure statement}

No potential conflict of interest was reported by the authors.

\section{Acknowledgements}

We are grateful to the anonymous reviewers for their helpful and informative comments. Any errors remain our own. 


\section{References}

Amy, J. J., \& Rowlands, S. (2018a). Legalised non-consensual sterilisation - Eugenics put into practice before 1945, and the aftermath. Part 1: USA, Japan, Canada and Mexico. Eur J Contracept Reprod Health Care, 23, pp. 121-129. doi:https://doi.org/10.1080/13625187.2018.1450973

Amy, J. J., \& Rowlands, S. (2018b). Legalised non-consensual sterilisation - Eugenics put into to practice before 1945, and the aftermath. Part 2: Europe. Eur J Contracept Reprod Health Caredoi:https://doi.org/10.1080/13625187.2018.1458227

Anonymous. (2010). Dignity denied: violations of the rights of HIV-positive women in Chilean health facilities. New York:

https://www.reproductiverights.org/sites/crr.civicactions.net/files/documents/chilerep ort_FINAL_singlepages.pdf

Anonymous. (2014). Forced sterilization in Chile. Retrieved Date Accessed, 2017 from $\underline{\text { www.reproductiverights.org/feature/forced-sterilization-in-chile }}$

Antelava, N. (2013). Forced sterilization of women in Uzbekistan New York: Open Society Foundations.

Badul, C. J., \& Strode, A. (2013). LM and Others v Government of the Republic of Namibia: The first sub-Saharan African case dealing with coerced sterilisations of HIV-positive women - Quo vadis? African Human Rights Law J, 13, pp. 214-228.

Beauchamp, T. L., \& Childress, J. F. (2013). Principles of biomedical ethics (7th ed.) New York: Oxford University Press.

Borrero, S., Zite, N., Potter, J. E., Trussell, J., \& Smith, K. (2013). Potential unintended pregnancies averted and cost savings associated with a revised Medicaid sterilization policy. Contraception, 88, pp. 691-696. 
Boyer, Y., \& Bartlett, J. (2017). External review: Tubal ligation in the Saskatoon Health Region: the lived experience of Aboriginal women. Saskatoon: https://www.saskatoonhealthregion.ca/DocumentsInternal/Tubal_Ligation_intheSaska toonHealthRegion_the_Lived_Experience_of_Aboriginal_Women_BoyerandBartlett July_22_2017.pdf

CBC. (2018, 14 November). Class-action lawyer told of 2 coerced sterilizations of Indigenous women in Manitoba. CBC News. Retrieved from https://www.cbc.ca/news/canada/manitoba/manitoba-indigenous-women-forced$\underline{\text { sterilization-lawsuit-1.4904421 }}$

Chi, I., \& Jones, D. B. (1994). Incidence, risk factors and prevention of poststerilization regret in women: an updated international review from an epidemiological perspective. Obstet Gynecol Surv, 49, pp. 722-732.

Clements, R. V. (2005). Informed choice: should we bin the consent form? Clinical Risk, 11, pp. 69-71.

Clinical Effectiveness Unit. (2014). Male and female sterilisation London: Faculty of Sexual and Reproductive Healthcare.

Cooper, B. (2016). Intersectionality. In L. Disch \& M. Hawkesworth (Eds.), The Oxford Handbook of Feminist Theory. Oxford: Oxford University Press.

Crozier, C. (2017, 10 March). External review on forced sterilization at Saskatoon hospitals "underfunded" says survivor. Aboriginal Peoples Television Network National News. Retrieved from http://aptnnews.ca/2017/03/10/external-review-on-forcedsterilization-at-saskatoon-hospitals-underfunded-says-survivor/

Curran, S. (2016). Intersectionality and human rights law: an examination of the coercive sterilisations of Romani women. Equal Rights Review, 16, pp. 132-159. 
Denbow, J. M. (2015). Governed through choice: autonomy, technology, and the politics of reproduction New York: New York University Press.

Dunn, M., Fulford, K. W. M., Herring, J., \& Handa, A. (2018). Between the reasonable and the particular: deflating autonomy in the legal regulation of informed consent to medical treatment. Health Care Analysisdoi:https://doi.org/10.1007/s10728-018$\underline{0358-\mathrm{x}}$

Durojaye, E. (2017). Involuntary sterilisation as a form of violence against women in Africa. J Asian \& African Studiesdoi:10.1177/0021909617714637

ERRC. (2016). Coercive and cruel: sterilisation and its consequences for Romani women in the Czech Republic (1966-2016) Budapest: European Roma Rights Centre.

FIGO. (2015). Ethical issues in obstetrics and gynecology. Retrieved Date from http://www.figo.org/sites/default/files/uploads/wgpublications/ethics/FIGO\%20Ethical\%20Issues\%202015.pdf4893.pdf

Fovargue, S., \& Mullock, A. (2016). The legitimacy of medical treatment. What role for the medical exception? Abingdon: Routledge.

Gilliam, M., Davis, S. D., Berlin, A., \& Zite, N. B. (2008). A qualitative study of barriers to postpartum sterilization and women's attitudes toward unfulfilled sterilization requests. Contraception, 77 , pp. 44-49.

Gostin, L. (1995). Informed consent, cultural sensitivity, and respect for persons. JAMA, 274, pp. 844-845.

Government of the Republic of Namibia v LM and others http://www.saflii.org/na/cases/NASC/2014/19.html No. SA 49/2012, SAFLII (Namibia: Supreme Court 2014).

Holt, E. (2005). Roma women reveal that forced sterilisation remains. Lancet, 365, pp. 927 928. 
Holt, E. (2012). Uzbekistan accused of forced sterilisation campaign. Lancet, 379, p 2415.

Hunt, L. M., \& de Voogd, K. M. (2007). Are good intentions good enough?: informed consent without trained interpreters. J Gen Int Med, 22, pp. 598-605.

ICW. (2009). The forced and coerced sterilization of HIV positive women in Namibiahttp://www.icw.org/files/The\%20forced\%20and\%20coerced\%20sterilization \%20of\%20HIV\%20positive\%20women\%20in\%20Namibia\%2009.pdf London: http://www.icw.org/files/The\%20forced\%20and\%20coerced\%20sterilization\%20of\% 20HIV\%20positive\%20women\%20in\%20Namibia\%2009.pdf

Manson, N. C., \& O’Neill, O. (2007). Rethinking informed consent in bioethics Cambridge: Cambridge University Press.

Moaddab, A., McCullough, L. B., Chervanak, F. A., Fox, K. A., Aagaard, K. M., Salmanian, B., ... Shamshirsaz, A. A. (2015). Health care justice and its implications for current policy of a mandatory waiting period for elective tubal sterilization. AJOG, 212, pp. 736-739.

Motej1, O. (2005). Final statement of the Public Defender of Rights in the matter of sterilisations performed in contravention of the law and proposed remedial measures. Brno: http://tbinternet.ohchr.org/Treaties/CERD/Shared\%20Documents/CZE/INT_CERD_ $\underline{\text { NGO_CZE } 70 \_8507 \text { E.pdf }}$

Nair, P. (2011). Litigation against the forced sterilization of HIV-positive women: recent developments in Chile and Namibia. Harvard Human Rights J, 23, pp. 223-231.

Patel, P. (2017). Forced sterilization of women as discrimination. Public Health Reviews, 38, $\mathrm{p} 15$.

Petchesky, R. P. (1979). Reproduction, ethics, and public policy: The Federal Sterilization Regulations. Hastings Center Reports, 9, pp. 29-41. 
Richardson, M. G., Hall, S. J., \& Zuckerwise, L. C. (2018). Postpartum tubal sterilization: making the case for urgency. Anaesthesia \& Analgesia, 126, pp. 1225-1231.

Rowlands, S., \& Amy, J.-J. (2018). Involuntary sterilisation: we still need to guard against it. BMJ Sex Reprod Health, 44, pp. 239-241.

Rowlands, S., \& Amy, J. J. (2018). Non-consensual sterilization of women living with HIV. Int J STD AIDSdoi:https://doi.org/10.1177/0956462418758116

Sharma, D. C. (2014). India's sterilisation scandal. Lancet, 384, pp. e68-e69.

Sifris, R. (2016). The involuntary sterilisation of marginalised women: power, discrimination and intersectionality. Griffith Law Review, 25, pp. 45-70.

Soares, L. C., \& Brollo, J. L. A. (2013). Family planning in Brazil: why not tubal sterilisation during childbirth? J Med Ethics, 39, pp. 710-712.

Solinger, T., \& Nakachi, M. (2016). Reproductive states: global perspectives on the invention and implementation of population policy New York: Oxford University Press.

Verkuyl, D. A., van Goor, G. M., Hanssen, M. J., Miedema, M. T., \& Koppe, M. (2011). The right to informed choice. A study and opinion poll of women who were or were not given the option of a sterilisation with their caesarean section. PLOS ONE, 6, p e14776.

Verkuyl, D. A. A. (2015). FIGO's ethical recommendations on female sterilisation will do more harm than good: a commentary. J Medical Ethics, 41, pp. 478-487.

Watson, K. (2014). Reframing regret. JAMA, 311, pp. 27-28.

WHO. (2014). Eliminating forced, coercive and otherwise involuntary sterilization Geneva: World Health Organization.

Wolfe, K. K., Wilson, M. D., Hou, M. Y., \& Creinin, M. D. (2017). An updated assessment of postpartum sterilization fulfilment after vaginal delivery. Contraception, 96, pp. $41-46$. 


\section{Pre acceptance version}

Zampas, C., \& Lamačková, A. (2011). Forced and coerced sterilization of women in Europe. Int J Gynecol Obstet, 114, pp. 163-166.

Zite, N. B., \& Wallace, L. S. (2011). Use of a low-literacy informed consent form to improve women's understanding of tubal sterilization. Obstet Gynec, 117, pp. 1160-1166. 